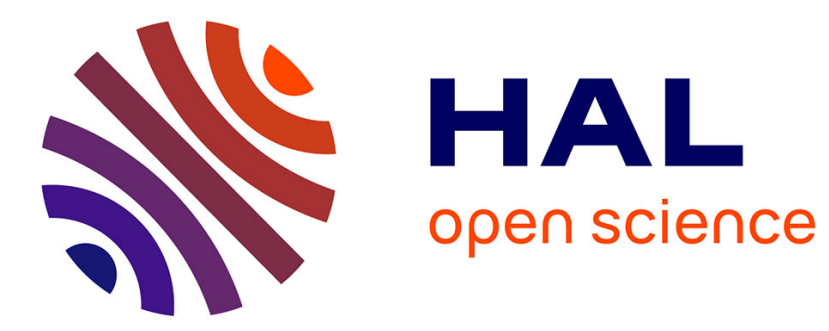

\title{
Vinylene-versus azomethine-bridged carbazole-based polymers for light emission and sensor applications
}

Achref Jebnouni, Nicolas Leclerc, Safa Teka, Dorsaf Mansour, Smida Jaballah

\section{To cite this version:}

Achref Jebnouni, Nicolas Leclerc, Safa Teka, Dorsaf Mansour, Smida Jaballah. Vinylene-versus azomethine-bridged carbazole-based polymers for light emission and sensor applications. Journal of Molecular Structure, 2021. hal-03405497

\section{HAL Id: hal-03405497 \\ https://cnrs.hal.science/hal-03405497}

Submitted on 27 Oct 2021

HAL is a multi-disciplinary open access archive for the deposit and dissemination of scientific research documents, whether they are published or not. The documents may come from teaching and research institutions in France or abroad, or from public or private research centers.
L'archive ouverte pluridisciplinaire HAL, est destinée au dépôt et à la diffusion de documents scientifiques de niveau recherche, publiés ou non, émanant des établissements d'enseignement et de recherche français ou étrangers, des laboratoires publics ou privés. 


\section{Vinylene-versus azomethine-bridged carbazole-based polymers for light emission and sensor applications}

Achref Jebnouni $^{\mathrm{a}^{*}}$, Nicolas Leclerc ${ }^{\mathrm{b}}$, Safa Teka $^{\mathrm{c}}$, Dorsaf Mansour ${ }^{\mathrm{c}}$, Nejmeddine Smida

$$
\text { Jaballah }^{\text {d,a }}
$$

${ }^{a}$ Laboratory of Interfaces and Advanced Materials, University of Monastir, Faculty of Sciences, Boulevard of the Environment, 5019 Monastir, Tunisia

${ }^{b}$ Institute of Chemistry and Processes for Energy, Environment and Health (ICPEES), European School of Chemistry, Polymers and Materials (ECPM), UMR 7515 University of StrasbourgCNRS, 25 rue Becquerel, Strasbourg 67087, France.

${ }^{c}$ Chemistry Department, College of Science, University of Hail, Kingdom of Saudi Arabia.

${ }^{d}$ Chemistry Department, College of Science and Humanities, Al Quwayiyah, Shaqra University, Saudi Arabia

\section{Abstract}

Two new carbazole-based soluble $\pi$-conjugated polymers were synthetized and investigated: P1 is a poly(p-phenylenevinylene) analogue and $\mathbf{P 2}$ is a poly-azomethine-type polymer. The macromolecular structures of $\mathbf{P 1}$ and $\mathbf{P 2}$ were confirmed by nuclear magnetic resonance and infrared spectroscopies. The effect of vinylene (in P1) and azomethine (in P2) $\pi$-linkers on thermal, optical and electrical properties of the two macromolecules was mainly studied. The differential scanning calorimetry and thermogravimetric analyses showed that both polymers are amorphous and better thermal stability was observed in the case of the azomethine containing polymer. The photophysical behavior of these $\pi$-conjugated systems were investigated by UVvisible absorption and photoluminescence spectroscopies. Schottky single-layer diodes and Organic Field-Effect Transistors (OFETs) using P1 and P2 as active layers were elaborated in order to study the electrical properties of these polymeric materials. P1 is a semi-conducting and fluorescent polymer, with a yellowish-green emission and a charge carrier mobility of $5.110^{-6}$ $\mathrm{m}^{2} /$ V.s making it a good candidate for organic light emitting devices (OLED) applications. However, the poly-azomethine P2, in its neutral state, is of little interest when compared to the polyvinylene derivative, due to its very low charge transport capacity and negligible fluorescence intensity. We demonstrate in this study that the electrical and optical properties of the polyazomethine $\mathbf{P 2}$ can be dramatically improved by nitrogen protonation of the azomethine linkers. Indeed, under exposure to trifluoroacetic acid (TFA) vapors, an emitted fluorescence that is a 
linear function of the amount of TFA added to the $\mathbf{P 2}$ solution was observed and a charge carrier mobility of $710^{-5} \mathrm{~m}^{2} / \mathrm{V}$.s was achieved. This opens the way for these azomethine-containing carbazole-based polymers to promising applications in electrical and fluorescence turn-on sensors.

Keywords: Semi-conducting polymers; $\pi$-linkers; Poly-azomethine; Photo-induced electron transfer (PET); fluorescence turn-on sensors; Organic Field-Effect Transistors (OFET).

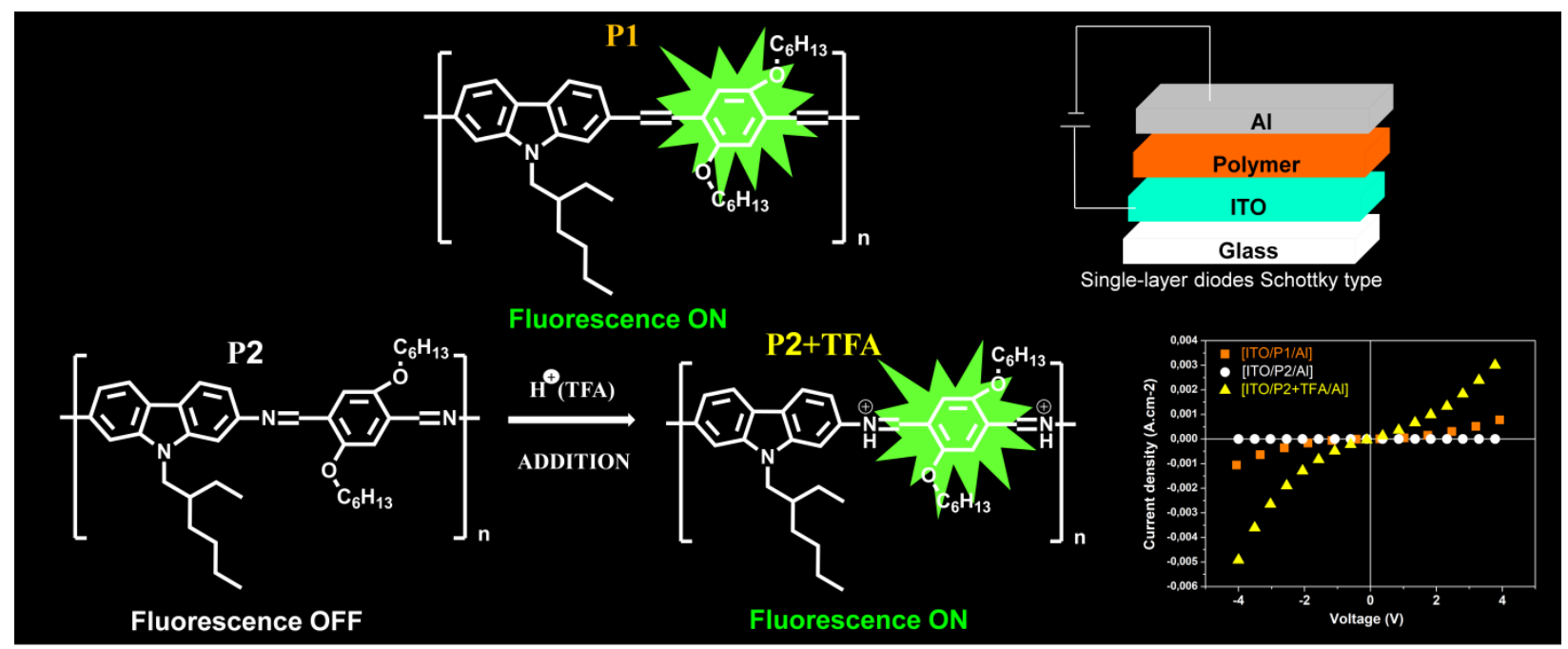

Graphical Abstract 


\section{Introduction}

In the last three decades, enormous progress has been made in investigating the $\pi$-conjugated semiconducting polymers. These macromolecular compounds and their composites $[1,2,3]$ are widely used as active layers in electronic devices such as organic light emitting diodes (OLEDs) [4], organic field-effect transistors (OFETs) [5], organic solar cells [6] and sensors [7]. In fact, the great deal of attention that the $\pi$-conjugated polymers receive is due to their low-cost and ease of synthesis and processing. Indeed, these organic materials are compatible with solution processing techniques [8], avoiding the expensive lithography and vacuum deposition steps required for the elaboration of inorganic semi-conducting thin films. The unique mechanical properties and film-forming quality of these polymers also expands the repertoire of tolerant substrates and allow the fabrication of flexible electronic devices [9]. However, the major characteristic justifying the huge interest in semi-conducting polymers is their adjustable molecular structure, benefiting from the richness of the organic synthesis, and therefore their tuneable opto-electronic properties [10]. Among the different conjugated moieties, $\mathrm{N}$ and 3,6disubstituted carbazole-based organic semiconductors have found applications in the emerging organic light emitting devices (OLED) field due to their unique optical properties, combined to a high air sensitive stability [11,12]. The further development of the more conjugated 2,7disubstituted carbazole derivative chemistry has accelerated their deep investigation for new applications such as organic photovoltaics (OPV) and sensors $[13,14]$. Thanks to the very rich chemistry developed around this unit, one can find a wide variety of functional groups and chemical units combined with the carbazole unit, such as vinylene linkers, electron donating thiophene and 2,2'-bithiophene groups, electron withdrawing benzothiadiazole units and many others, can be found $[15,16,17]$. However, there is still a need to develop new functional groups to achieve innovative and unique optoelectronic properties, broadening consequently the scope of possible applications. $\pi$-conjugated materials involving azomethine $(-\mathrm{N}=\mathrm{CH}-)$ bridges are less investigated by researchers than their all carbon vinylene-based material counterparts. Indeed, in their neutral state, poly-azomethines are assumed to be non-fluorescent materials [18] with low very charge mobility and conductivity [19]. However, they own specific properties related to the presence of the lone pair of electrons on the nitrogen atom. In fact, chelating the Schiff-base with some substances such as silver $(\mathrm{Ag})$, Iron $\left(\mathrm{Fe}^{3+}\right)$, aluminium $(\mathrm{Al})$, or protonating it with acids greatly enhanced their optical and electrical properties, making them promising candidates for sensor applications [20,21,22]. In addition, azomethine-derivatives are known for their easy preparation and their high thermal and environmental stabilities $[23,24]$. 
Recently, we reported the design and synthesis of new carbazole and anthracene-based small molecules [25]. The comparison between both conjugated bridges allowed us to highlight drastically different properties. Among them, we demonstrated that the Schiff-base protonation in azomethine derivative leads to a turn-on of the fluorescence, a naked eye remarkable visible colour change and a significative increase of the hole mobility in thin films. In an attempt to further develop this class of materials, herein, we designed, synthesized and investigated two new conjugated polymers, based on 2,7-bisfunctionnalized carbazole with the hydroquinone unit as comonomer. A first derivative is using a vinylene-group as $\pi$-conjugated bridge (P1) while the second material is using an azomethine bridge (P2) (Scheme 1). In addition to the excellent photochemical stability [26] and good hole transport properties of the carbazole [27], the use of hydroquinone has been motivated by the high electroluminescence quantum yields, the high thermal stability and the good electron transport properties of hydroquinone-based materials [28]. This work aims to study the effect of replacing the vinylene linkers (P1) by azomethine ones (P2), on the thermal, optical and electrical properties of the $\pi$-conjugated carbazole-based polymers .We also explored the effect of protonating the poly-azomethine with trifluoroacetic on photophysical and electrical properties of this polymer $\mathbf{P 2}$.

\section{Experimental section}

\subsection{Reagents and Instruments}

All reagents and solvents were purchased from Sigma-Aldrich and were used without purification except toluene ( $\geq 99.5 \%)$, tetrahydrofurane (THF) $(\geq 99.0 \%)$, methanol $(\geq 90 \%), \mathrm{N}, \mathrm{N}$ dimethylformamide (DMF) ( $\geq 99.0 \%$ ), and acetone ( $\geq 99.0 \%)$ which were dried and distilled under reduced pressure. ${ }^{1} \mathrm{H}$ NMR and ${ }^{13} \mathrm{C}$ NMR spectra were recorded on a Bruker Avance III 400MHz NMR spectrometer. Differential scanning calorimetry analysis were conducted using a METTLER Toledo DSC 1 instrument, with a scanning rate of $10^{\circ} \mathrm{C} / \mathrm{min}$. Thermogravimetric analyses were made using a Hi-Res TGA Q5000 apparatus from TA Instruments under a flow of helium $(25 \mathrm{~mL} / \mathrm{min})$. Uv-vis absorption spectra were recorded in chloroform diluted solutions $\left(5.10^{-5} \mathrm{M}\right)$ and in thin solid film state by spin coating a chloroform solution $\left(2.10^{-2} \mathrm{M}\right)$ onto glass substrate. The film thicknesses were measured using a mechanical profilometer Veeco Dek-tak80. Chloroform very diluted solutions $\left(2.10^{-6} \mathrm{M}\right)$ were excited with a $450 \mathrm{~W}$ Xenon lamp in order to study the emission of the materials. In the fluorescence quantum yields measurements, absorbance of the sample solutions was kept below 0.05 to avoid inner filter effect. Both sample and reference solutions were excited at the same wavelength $(400 \mathrm{~nm})$. The electrochemical behavior of the macromolecules was studied by cyclic voltammetry. A platinum wire and an 
$\mathrm{Ag} / \mathrm{Ag}+$ were used respectively as a counter electrode and a reference electrode in a $0.1 \mathrm{~mol} . \mathrm{L}^{-1}$ solution of tetrabutylammonium tetrafluoroborate $\left[\mathrm{NBu}_{4}\right]\left[\mathrm{BF}_{4}\right]$ in dichloromethane.

\subsection{Polymer synthesis}

\subsubsection{Synthesis of the polymer P1 via Wittig polycondensation:}

N-2-ethylhexyl-2,7-diformylcarbazole (M1) (1 mmol, 0.335g), triphenyl phosphine salt of hydroquinone (M3) (1 mmol, 0.900g) and Potassium tert-butoxide (4 mmol, 0.448g) were dissolved in anhydrous THF $(8 \mathrm{~mL})$. The solution was refluxed at $70^{\circ} \mathrm{C}$ with stirring under nitrogen atmosphere for $48 \mathrm{~h}$. The solution was then cooled to the room temperature and acidified with $3 \mathrm{~mol}$. $\mathrm{L}^{-1}$ aqueous hydrochloric acid in order to neutralize the excess of the base and to hydrolyse the triphenyl phosphine salt end-chains into methyl group. The polymer was extracted with chloroform, washed with distilled water and purified by repeated precipitation in methanol and dissolution in chloroform. The polymer P1 was obtained as an orange powder soluble in common organic solvents with a yield of $45 \%$. FTIR $\left(\mathrm{cm}^{-1}\right): 3056(\mathrm{w}$, aromatic and vinylic C-H stretching), 2926, 2855 (s, aliphatic C-H stretching), 1746 (m, Ar-CHO end-group stretching), 1683 (m, C=C stretching), 1597, 1494, 1455 (m, C=C aromatic stretching), 1324 (m, C-N stretching), 1196 (s, C-O-C asymmetric stretching), 1028 (m, C-O-C symmetric stretching), 963 (m, trans-HC=CH out-of-plane bending), 849 (w, cis-HC=CH out-of-plane bending), 798 (m, aromatic $\mathrm{C}-\mathrm{H}$ out-of-plane bending). ${ }^{1} \mathrm{H} \mathrm{NMR}\left(400 \mathrm{MHz}, \mathrm{CDCl}_{3}, \mathrm{ppm}\right.$ ): $\delta=10.1$ and 10.5 (m, CHO end group), 8.2-6.5 (m, aromatic and vinylic protons), 4.3-3.4 (m, N$\mathrm{CH}_{2}$ and $\mathrm{O}-\mathrm{CH}_{2}$ ), 2.9 (m, Ar- $\mathrm{CH}_{3}$ end groups), 2.3-0.7 (m, aliphatic protons). We note that the $\mathrm{Ar}-\mathrm{CH}_{3}$ end groups were formed by hydrolysis of the triphenyl phosphine salt.

\subsubsection{Synthesis of the polymer $P 2$ via diamine polycondensation:}

On warm water-bath, 2 mmoles $(0.669 \mathrm{~g})$ of 2,5-bis(hexyloxy)terephtaldehyde (M4) were dissolved in $3 \mathrm{~mL}$ of tetrahydrofuran and $6.5 \mathrm{~mL}$ of glacial acetic acid. A warm solution of N-2ethylhexyl-2,7-diaminocarbazole (M2) $(618,44 \mathrm{mg}$, 2mmoles) in $4 \mathrm{~mL}$ of glacial acetic acid was then added and the mixture was then allowed to react. In about 10 seconds, an orange precipitate was formed. After 10 minutes, the solution was diluted in $100 \mathrm{~mL}$ of anhydrous methanol; the precipitate is filtered and washed successively with water, methanol and diethyl ether. The obtained powder was finally reprecipitated five times from tetrahydrofuran-methanol and dried under vacuum to obtain $360 \mathrm{mg}$ of orange powder with a yield of $30 \%$ [29]. FTIR $\left(\mathrm{cm}^{-1}\right): 3019$ (w, aromatic and vinylic C-H stretching), 2923, 2856 (w, aliphatic C-H stretching), 1738 (s, ArCHO end-group stretching), $1587(\mathrm{w}, \mathrm{C}=\mathrm{N}$ symmetric stretching), 1456, 1423 (m, C=C aromatic stretching), 1371 (m, C-N stretching), 1203 (s, H-C=N in-plane bending), 1116 (w, C- 
O-C asymmetric stretching), 1023 (w, C-O-C symmetric stretching), 793 (m, aromatic $\mathrm{C}-\mathrm{H}$ out-of-plane bending). ${ }^{1} \mathrm{H} \mathrm{NMR}\left(400 \mathrm{MHz}, \mathrm{CDCl}_{3}, \mathrm{ppm}\right): \delta=10.5$ (m, CHO end group), 9.17 (m, $-\mathrm{N}=\mathrm{CH}-$ ), 8.11-6.43 (m, aromatic and vinylic protons), 4.07-3.34 (m, N-CH $1.95-0.80$ (m, aliphatic protons).

\subsubsection{Method for determining the polymers average molecular weights}

By identifying the nature of the chain end-caps (Figure S.1) using the ${ }^{1} \mathrm{H}$ NMR spectrum (Figure S.3), we were able to determine the number average molecular weight $(\bar{M} \mathrm{n})$ of the polymer P1. Indeed, the comparison of the integrals of the proton peaks of the end-chains (Ar$\mathrm{CH}_{3}$ and $\left.\mathrm{CHO}\right)$ with those of the repeating units $\left(-\mathrm{O}-\mathrm{CH}_{2}\right.$ - and $\left.\mathrm{N}-\mathrm{CH}_{2}\right)$ allows us to calculate the degree of polymerization $\left(\bar{X}_{\mathrm{n}}\right)$ for this polymer and then the number average molecular mass can be determined according to the following formula:

$$
\bar{M}_{\mathrm{n}}=\bar{X}_{\mathrm{n}} \mathrm{M}_{0}+\mathrm{M}_{\mathrm{e}} \quad \mathrm{Eq}(1)
$$

With: $\bar{X}_{\mathrm{n}}$ : Degree of polymerization.

$\mathrm{M}_{0}$ : Molar mass of the repeating unit.

Me: Molar mass of end chain.

i) The percentages of $\mathrm{CHO}$ and $\mathrm{Ar}-\mathrm{CH}_{3}$ end groups were determined by comparing the integrals of the proton signals of these groups and by the following equation:

$\%\left(\mathrm{Ar}-\mathrm{CH}_{3}\right)=100 * \mathrm{I}\left(\mathrm{Ar}-\mathrm{CH}_{3}\right) /\left[\left(\mathrm{I}\left(\mathrm{Ar}-\mathrm{CH}_{3}\right)+\mathrm{I}(\mathrm{CHO}) * 3\right]\right.$ with:

$\mathrm{I}\left(\mathrm{Ar}-\mathrm{CH}_{3}\right)$ : The signal integral relative to $\mathrm{Ar}-\mathrm{CH}_{3}$ protons on the ${ }^{1} \mathrm{H}$ NMR spectrum.

$\mathrm{I}(\mathrm{CHO})$ : The signal integral relative to $\mathrm{CHO}$ protons on the ${ }^{1} \mathrm{H}$ NMR spectrum.

This gives an $\mathrm{Ar}-\mathrm{CH}_{3}$ percentage of $80.8 \%$ and $\mathrm{CHO}$ of $19.2 \%$.

ii) The number of protons in the $\mathrm{N}-\mathrm{CH}_{2}$ and $\mathrm{O}-\mathrm{CH}_{2}$ groups in the repeating units is equal to 6 . So, in a polymer sample containing $\mathrm{N}$ macromolecular chain, the number of protons in $\mathrm{N}-\mathrm{CH}_{2}$ and $\mathrm{O}-\mathrm{CH}_{2}$ groups is equal to $\mathrm{N}^{*}\left(6 \bar{X}_{\mathrm{n}}\right)$, the number of protons in the $\mathrm{Ar}-\mathrm{CH}_{3}$ end groups is equal to $(6 \mathrm{~N} * 0.808)$ and the number of protons in $\mathrm{CHO}$ end groups is of $\left(2 \mathrm{~N}^{*} 0.192\right)$.

Thus, $\mathrm{I}\left(\mathrm{N}-\mathrm{CH}_{2}+\mathrm{O}-\mathrm{CH}_{2}\right) /\left[\mathrm{I}\left(\mathrm{Ar}-\mathrm{CH}_{3}\right)+\mathrm{I}(\mathrm{CHO})\right]=\mathrm{N}^{*}\left(6 \bar{X}_{\mathrm{n}}\right) /\left[6 \mathrm{~N}^{*} 0,808+2 \mathrm{~N} * 0,192\right]$

where: $\mathrm{I}\left(\mathrm{N}-\mathrm{CH}_{2}+\mathrm{O}-\mathrm{CH}_{2}\right), \mathrm{I}\left(\mathrm{Ar}-\mathrm{CH}_{3}\right)$ and $\mathrm{I}(\mathrm{CHO})$ are the integrations of the signals corresponding to the $\mathrm{N}-\mathrm{CH}_{2}$ and $\mathrm{O}-\mathrm{CH}_{2}$ protons, $\mathrm{Ar}-\mathrm{CH}_{3}$ protons and $\mathrm{CHO}$ protons in the ${ }^{1} \mathrm{H}$ NMR spectrum.

Therefore: $\bar{X}_{\mathrm{n}}=1,06 * \mathrm{I}\left(\mathrm{N}-\mathrm{CH}_{2}+\mathrm{O}-\mathrm{CH}_{2}\right) /\left[\mathrm{I}\left(\mathrm{Ar}-\mathrm{CH}_{3}\right)+\mathrm{I}(\mathrm{CHO})\right]$ which give $\bar{X}_{\mathrm{n}}=7$.

iii) The molar mass of the repeating unit $\mathrm{M}_{0}=605 \mathrm{~g} \cdot \mathrm{mol}^{-1}$.

The molar mass of the end-chains $\mathrm{M}_{\mathrm{e}}=335^{*} 0,192+306 * 0,808=311 \mathrm{~g}^{\mathrm{mol}}{ }^{-1}$ 
Therefore, the number-average molar weight of P1, calculated according to $\mathbf{E q ( 1 ) , ~ i s ~ e q u a l ~ t o ~}$ 4550 g. $\mathrm{mol}^{-1}$.

The ${ }^{1} \mathrm{H}$ NMR spectrum of the polymer P2 (Figure S.3) reveals the signals of azomethine linkages $(-\mathrm{CH}=\mathrm{N}-)$ and $\mathrm{CHO}$ chain at 9.17 and at $10.5 \mathrm{ppm}$, respectively.

The degree of polymerization $\left(\bar{X}_{\mathrm{n}}\right)$ of the polymer $\mathbf{P 2}$ was calculated by comparing the integral of the peak relative to the protons $\mathrm{CHO}$ (chain ends) with that of the protons in the $-\mathrm{N}=\mathrm{CH}$ linkers:

In a polymer sample containing $\mathrm{N}$ macromolecular chain, the number of protons in the $-\mathrm{N}=\mathrm{CH}-$ groups in the sample is equal to $\mathrm{N}^{*}\left(2 \bar{X}_{\mathrm{n}}\right)$, the number of protons of the end groups $\mathrm{CHO}$ is equal to $2 \mathrm{~N}$.

Thus, $\mathrm{I}(-\mathrm{N}=\mathrm{CH}-) / \mathrm{I}(\mathrm{CHO})=\mathrm{N}^{*}\left(2 \bar{X}_{\mathrm{n}}\right) / 2 \mathrm{~N}$.

where $\mathrm{I}(\mathrm{CHO})$ and $\mathrm{I}(-\mathrm{N}=\mathrm{CH}-)$ are the integrations of the signals corresponding to the $\mathrm{CHO}$ and $\mathrm{N}=\mathrm{CH}$ protons in the ${ }^{1} \mathrm{H}$ NMR spectrum.

Therefore: $\bar{X}_{\mathrm{n}}=\mathrm{I}(-\mathrm{N}=\mathrm{CH}-) / \mathrm{I}(\mathrm{CHO})$ which give $\bar{X}_{\mathrm{n}}=20$.

Thus, the number-average molar mass calculated according to Eq (1) is equal to $12470 \mathrm{~g}^{\mathrm{mol}}{ }^{-1}$.

(in P2, the molar mass of the repeating unit $\mathrm{M}_{0}=607 \mathrm{~g} \cdot \mathrm{mol}^{-1}$; the molar mass of the end-chains $\left.\mathrm{M}_{\mathrm{e}}=334 \mathrm{~g} \cdot \mathrm{mol}^{-1}\right)$.

\subsection{Fabrication and characterization of the Organic Field-Effect Transistors (OFET) and} Schottky single-layer diodes:

\section{Fabrication and characterization of the Schottky single-layer diodes}

Solutions of the polymers (2. $10^{-2} \mathrm{M}$ in chloroform) were used to form films with a thickness of $60 \mathrm{~nm}$ by spin-coating $(2500 \mathrm{rpm})$ onto indium tin oxide (ITO) glass. The films were annealed at $40^{\circ} \mathrm{C}$ for 60 minutes. A thin layer $(150 \mathrm{~nm})$ of aluminum (Al) was then deposited by thermal evaporation $\left(3 \times 10^{-6}\right.$ Torr). The current-voltage (I-V) measurements of the diodes were extracted with a Keithley 236 source meter using the $\mathrm{Al}$ as a cathode and the ITO as an anode.

\section{Fabrication and characterization of OFETs}

The electrical characteristics of organic field-effect transistors (OFET) configuration (bottom contact, bottom gate configuration) were used to study the charge transport in the thin films.

The OFETs were prepared on commercially pre-printed test devices with contacts (drain and source) that are composed respectively of $10 \mathrm{~nm}$ ITO and $30 \mathrm{~nm}$ thick gold bilayers [30]. 


\section{Results and discussion}

\subsection{Synthesis and characterization of the carbazole based polymers}

We have synthesized two carbazole-based monomers N-(2-ethylhexyl)-2,7-bisformylcarbazole and N-(2-ethylhexyl)-2,7-diaminocarbazole (M1 and M2, Scheme 1) according to a procedure described in our previous work [25] and two hydroquinone monomer derivatives: Triphenyl phosphine salt of hydroquinone and 2,5-bis(hexyloxy)terephtaldehyde (M3 and M4, Scheme 1) by following synthesis protocols described in the literature [31,32].

In order to properly compare the properties of the two polymers, the two carbazole-based monomers carry the same branched ethyl-hexyl side chain, supposed to bring enough solubility. M1 is reacted via a Wittig reaction while M2 is reacted through a diamine polycondensation, leading to $\mathbf{P 1}$ and P2, respectively (Scheme 1). Both macromolecular structures were confirmed by Fourier-transform infrared spectroscopy (FTIR) (Figure S.2) and proton nuclear magnetic resonance $\left({ }^{1} \mathrm{H}\right.$ NMR) (Figure S.3).
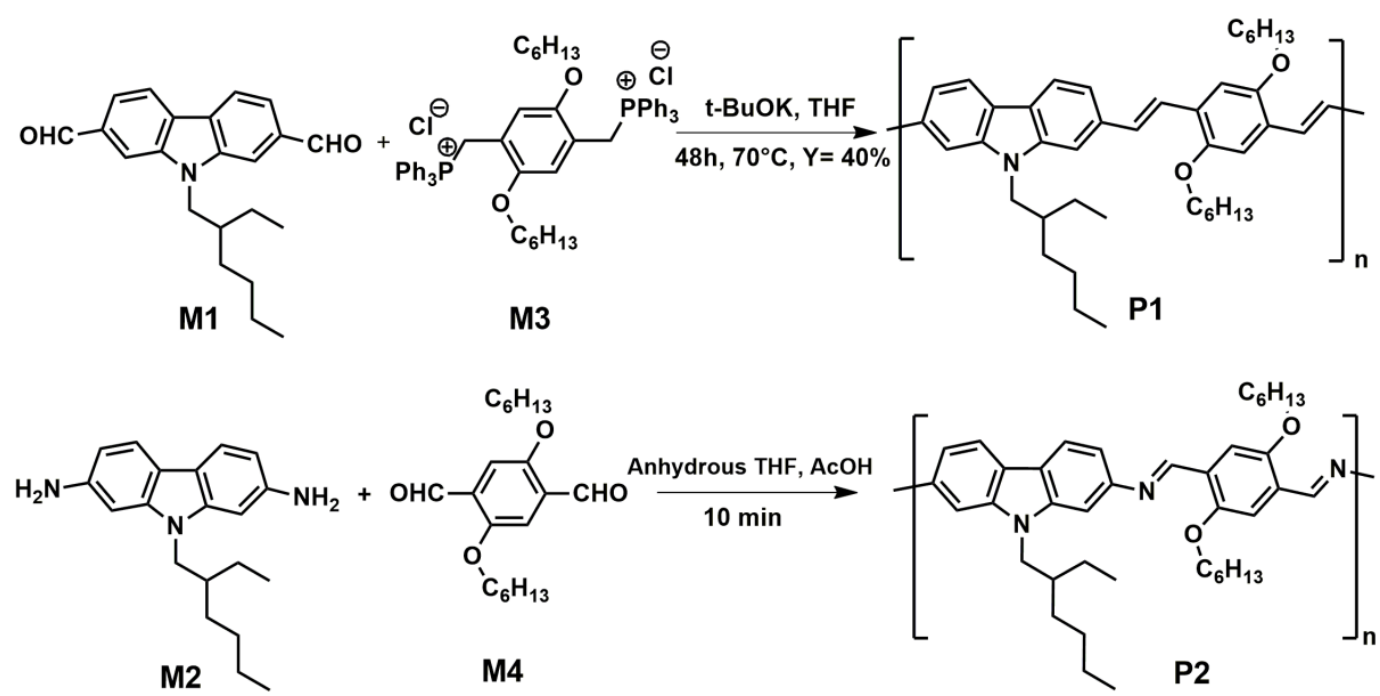

Scheme 1. Synthesis routes of the polymers $\mathbf{P 1}$ and $\mathbf{P 2}$

Both polymers are soluble in common solvents used in the elaboration of organic thin films by spin-coating process, such as THF, $\mathrm{CH}_{2} \mathrm{Cl}_{2}, \mathrm{CHCl}_{3}$, dichlorobenzene.

Thermal properties of the two polymers were evaluated using differential scanning calorimetry (DSC) and thermogravimetric analysis (TGA) (Figure S.4). The replacement of the vinylene bridge $(-\mathrm{CH}=\mathrm{CH}-)$ between hydroquinone and carbazole moieties in polymer $\mathbf{P 1}$ by the azomethine $(-\mathrm{CH}=\mathrm{N}-)$ linkage in polymer $\mathbf{P 2}$ significantly improve the thermal stability of the macromolecule and increase the decomposition temperature from $370^{\circ} \mathrm{C}$ for $\mathbf{P 1}$ to $407^{\circ} \mathrm{C}$ for $\mathbf{P 2}$. In fact, similar effect of azomethine unit incorporation on the thermal properties of $\pi$-conjugated materials was previously reported [25]. Differential Scanning Calorimetry analysis shows similar 
trends in the polymer thermal transitions. Indeed, they are both amorphous polymers, they exhibit glass transitions at $135^{\circ} \mathrm{C}$ and $151^{\circ} \mathrm{C}$ for $\mathbf{P 1}$ and $\mathbf{P 2}$, respectively.

\subsection{Absorption properties}

The ultraviolet-visible absorption (UV-vis) of the two compounds (P1 and P2) was studied in chloroform diluted solutions and in solid thin films. The spectra are shown in Figure 1 (a) and the absorption data are summarized in table 1.

The optical band gaps $(E g)$ of the conjugated macromolecules were evaluated using the Tauc relation [33]: $(\alpha h v)=\mathrm{A}(h v-E g)^{1 / 2}$, where $h v$ is the absorbed photon energy and $\alpha$ is the corresponding absorption coefficient. The $E g$ were obtained from extrapolation to $\alpha=0$ of the straight line portion in the $(\alpha h v)^{2}$ versus $h v$ plot (Figure 1 (b)).

In diluted chloroform solutions, UV-visible absorption spectrum of $\mathbf{P 1}$ consists of two bands, at $257 \mathrm{~nm}$ and $452 \mathrm{~nm}$, whereas $\mathbf{P 2}$ spectrum shows three bands centered at $460 \mathrm{~nm}, 312 \mathrm{~nm}$ and $287 \mathrm{~nm}$.

The main absorption band centered around $450-460 \mathrm{~nm}$ in both polymers is attributed to a $\pi-\pi^{*}$ transition [34]. The absorption bands in the range of $257-312 \mathrm{~nm}$ are attributed to the $\mathrm{n}-\pi^{*}$ transition of the carbazole units. As seen in Figure 1 (a), the UV-visible absorption spectrum of $\mathbf{P 2}$ is red shifted (13 nm) and broadened compared with that of P1. This displacement is due to the electron-withdrawing effect of the azomethine $(-\mathrm{CH}=\mathrm{N}-)$ linkages [35] present in the main chain of the poly-azomethine P2, which probably induces a slight internal charge transfer responsible of this red-shift. Consequently, the optical bandgap is decreased in P2 as regards to P1, from $2.48 \mathrm{eV}$ to $2.44 \mathrm{eV}$. [36]

In solid thin films, the absorption spectra of $\mathbf{P 1}$ and $\mathbf{P 2}$ are broadened and red-shifted as compared to those in diluted solutions. In addition, the two polymers exhibit a slight vibronic structure, generally attributed to the planarization and ordering of the polymers in solid state. This behavior is generally associated with an interchain $\pi$-stacking increase resulting in a redshift of the UV-Visible absorption spectrum [36]. In this respect, one can noticed that when going from solution to the solid state, $\mathbf{P 1}$ seems to reach a better order with a more significant bandgap reduction (i.e. a higher red-shift of the absorption onset: $31 \mathrm{~nm}$ for P1 versus $15 \mathrm{~nm}$ for P2) and a slightly more pronounced vibronic structure than polymer P2. This behavior suggests stronger intermolecular interactions which can be related to a higher planarity in the macromolecular structure of P1. As a consequence, the calculated optical bandgaps in thin films are $2.34 \mathrm{eV}$ and $2.37 \mathrm{eV}$ for $\mathbf{P 1}$ and $\mathbf{P 2}$, respectively. 
(a)

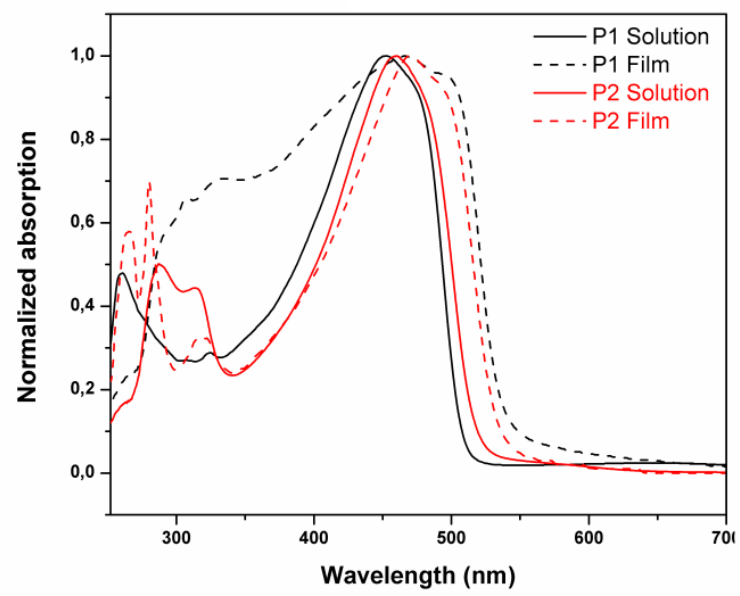

(b)

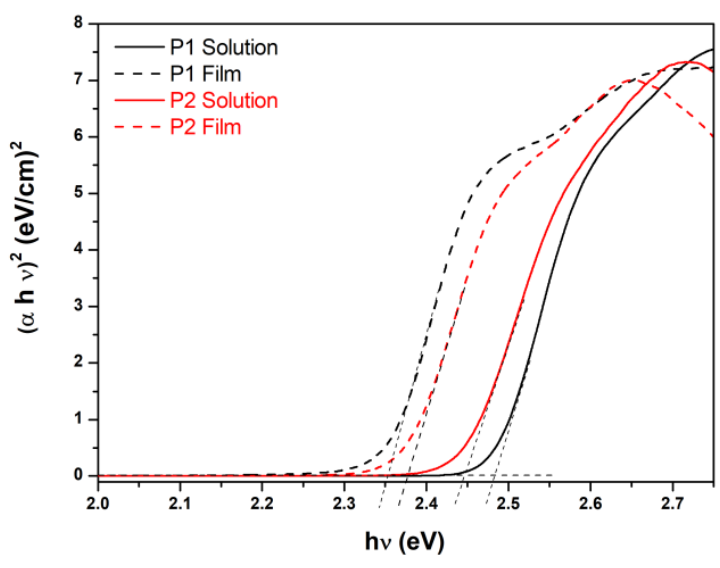

Figure 1. Absorption spectra (a) and the $(\alpha h v)^{2}$ vs. hv plot (b) of the $\mathbf{P 1}$ and $\mathbf{P 2}$ in thin films in comparison with those of diluted solutions.

Table 1. UV-visible spectroscopic parameters of $\mathbf{P 1}$ and $\mathbf{P 2}$ in diluted solutions and in thin films.

\begin{tabular}{lccccc}
\hline \multicolumn{5}{c}{ Dilute solutions } \\
\hline & $\lambda_{\max }(\mathbf{n m})^{(\mathbf{a})}$ & $\varepsilon_{\max }\left(\mathbf{1 0}^{\mathbf{4}} \cdot \mathbf{M}^{-\mathbf{1}} \cdot \mathbf{c m}^{-\mathbf{1}}\right)^{(\mathbf{b})}$ & $\mathbf{F W H M}(\mathbf{n m})^{(\mathbf{c})}$ & $\lambda_{\text {onset }}(\mathbf{n m})^{(\mathbf{d})}$ & $\mathbf{E}_{\mathbf{g}-\text { opt }}(\mathbf{e V})^{(\mathbf{e})}$ \\
\hline $\mathbf{P 1}$ & 257,452 & $0.38,0.72$ & 142 & 508 & 2.48 \\
\hline $\mathbf{P 2}$ & $287,312,460$ & $3.48,3.1,6.96$ & 100 & 521 & 2.44 \\
\hline
\end{tabular}

Thin films

\begin{tabular}{lcccc}
\hline & $\lambda_{\max }(\mathbf{n m})$ & $\mathbf{F W H M}(\mathbf{n m})$ & $\boldsymbol{\lambda}_{\text {onset }}(\mathbf{n m})$ & $\mathbf{E}_{\text {g-opt }}(\mathbf{e V})$ \\
\hline $\mathbf{P 1}$ & 328,465 & 221 & 539 & 2.34 \\
\hline $\mathbf{P 2}$ & $265,280,316,470$ & 111 & 536 & 2.37 \\
\hline
\end{tabular}

(a) Absorption peak maximum, (b) Molar extinction coefficient, (c) Full width at half maximum of the absorption spectrum in solution, (d) Absorption onset, (e) Optical band-gap energy

\subsection{Photoluminescence properties}

The fluorescence spectra of the carabzole-based polymers were recorded in chloroform diluted solutions $\left(2.10^{-6} \mathrm{M}\right)$ at room temperature and the results were depicted in Figure 2. Under 365 nm UV lamp, diluted solution of P1 exhibits yellowish-green emission, however the polyazomethine P2 was found almost non-photoluminescent. The spectrum of P1 shows only one broad band with a maximum at $506 \mathrm{~nm}$ and a very week emission band was detected for the $\mathbf{P 2}$ 
solution Figure 2 (a). The chromaticity coordinates of the emitted light for the fluorescent polymer P1 are $\mathrm{x}=0.32$ and $\mathrm{y}=0.43$, representing a yellowish-green emission in the $1931 \mathrm{CIE}$ diagram (Figure $2(b))$.

(a)

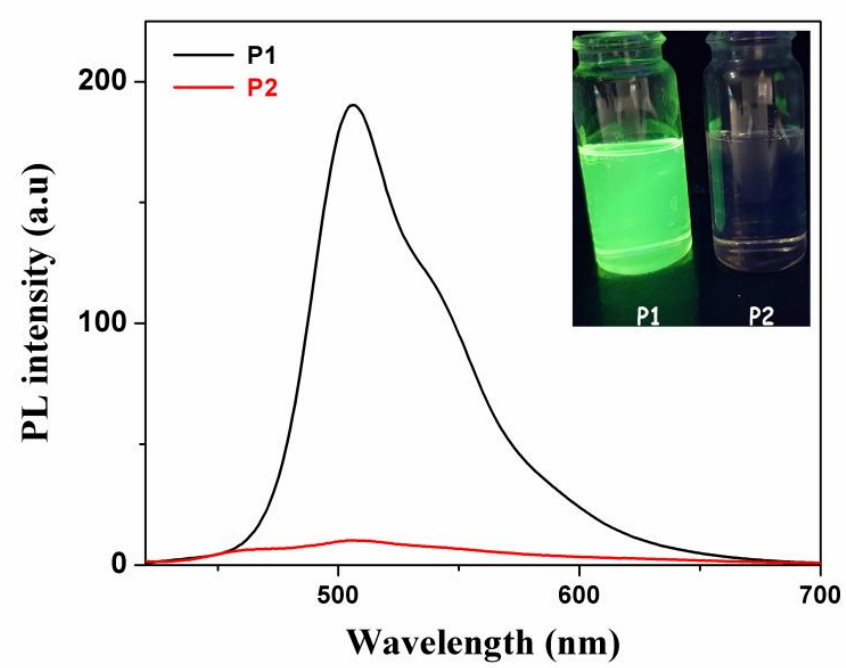

(b)

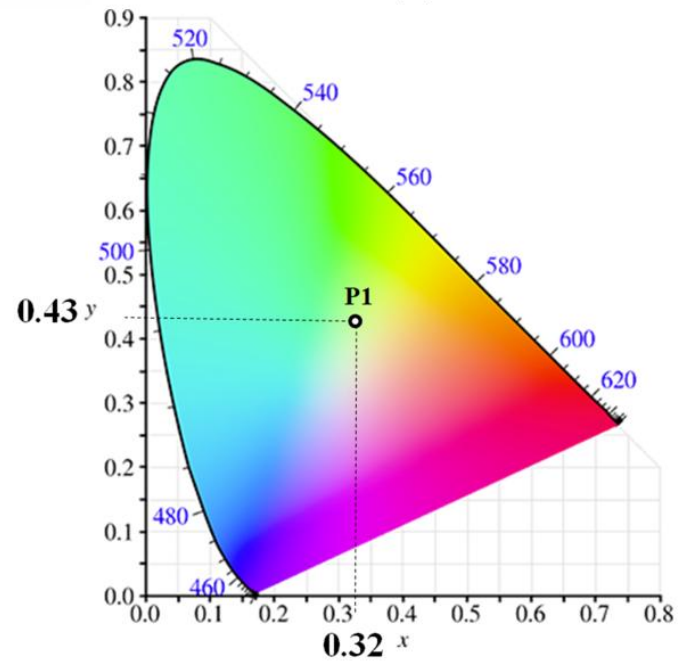

Figure 2. PL spectra and photograph under UV illumination of $\mathbf{P 1}$ and $\mathbf{P} 2$ in chloroform diluted solutions $\left(2.10^{-6} \mathrm{M}\right)$ (a) and the chromaticity coordinates of the emitted light of P1 (b)

The fluorescence quantum yield ( $(\exp )$ of $\mathbf{P 1}$ was calculated in solution by using cresyl violet as a reference $\left(\phi=0.5\right.$ in ethanol, $\left.\lambda_{\mathrm{exc}}=400 \mathrm{~nm}\right)$ [37] and the estimated value was of $60 \%$. The quenching of the $\mathbf{P 2}$ photoluminescence is probably due to a highly efficient photo-induced electron-transfer (PET) [38]. In fact, such fluorescence quenching process can be observed in molecules containing non-bonding electron pair which is linked through a short spacer to the fluorophore. In particular, the isomerized $\mathrm{C}=\mathrm{N}$ double bond of the Schiff-base in the excited state is one of the most known systems where the PET phenomenon can take place [39]. The electron-donating groups (the nitrogen atom of the Schiff-base e.g.) generally contains a relatively high-energy non-bonding electron pair. When photo-exciting an electron from the highest occupied molecular orbital (HOMO) to the lowest unoccupied molecular orbital (LUMO), a hole is left in the HOMO. The molecule is then deexcited via an electron transfer from the non-bonding electron pair of the nitrogen atom to the HOMO of the excited fluorophore and the deactivation of the excited state is consequently non-radiative [40]. The proposed PET mechanism in $\mathbf{P 2}$ in comparison with the fluorescence mechanism in P1 is presented in Figure S.5. PET phenomenon in $\mathbf{P 2}$ make the photoluminescent polymer suitable material for 
application in different areas of chemistry such as artificial and natural photosynthesis, charge separation processes in photovoltaics, photoluminescent sensors and switches [41,42].

\subsection{HOMO/ LUMO levels}

The electrochemical properties of the two polymers were studied by cyclic voltammetry in chloroform solutions and scanned at a scan rate of $100 \mathrm{mV} \mathrm{s}^{-1}$. A Pt wire was used as counter electrode and $\mathrm{Ag} / \mathrm{Ag}+$ as reference electrode in a $0.1 \mathrm{~mol} . \mathrm{L}^{-1}$ solution of tetrabutylammonium tetrafluoroborate.

The obtained cyclic voltammograms are shown in Figure S.6. The electrochemical features, the Highest Occupied Molecular Orbital (HOMO), the Lowest Unoccupied Molecular Orbital (LUMO) and the electrochemical band-gap values $\left(E_{g-e l}\right)$, were calculated from the electrochemical onset potentials according to a method described in the literature, by assuming that the energy level of the ferrocene/ferrocenium is $4.8 \mathrm{eV}$ below the vacuum level the HOMO energy level $\left(E_{\text {НомO }}\right)$, LUMO energy level $\left(E_{L U M O}\right)$ and the electrochemical gap $\left(E_{g-e l}\right)$ were calculated according to the following equations: [43]

$E_{\text {НОмо }}(\mathrm{IP}$, ionization potential $)=-\left(\mathrm{V}_{\text {onset-ox }}-\mathrm{V}_{\mathrm{Foc}}+4.8\right) \mathrm{eV}$

$E_{L U M O}(\mathrm{EA}$, electron affinity $)=-\left(\mathrm{V}_{\text {onset-red }}-\mathrm{V}_{\text {Foc }}+4.8\right) \mathrm{eV}$

$E_{\text {g-el }}=\left(E_{\text {LUMO }}-E_{\text {HOMO }}\right) \mathrm{eV}$

The $\mathrm{V}_{\text {Foc }}$ is the ferrocene half-wave potential $(0.46 \mathrm{~V}), \mathrm{V}_{\text {onset-red }}$ is the reduction onset, $\mathrm{V}_{\text {onset-ox }}$ is the oxidation onset and all potentials were measured versus $\mathrm{Ag} / \mathrm{Ag}+$. The obtained electrochemical values are illustrated in table 2. The obtained results showed that the oxidation potential of $\mathbf{P 2}$ was slightly increased as compared to that of $\mathbf{P 1}$, although we can see a significant increase of the reduction potential of the poly-azomethine. As a result, the electrochemical band-gap is slightly reduced from $2.49 \mathrm{eV}$ for $\mathbf{P 1}$ to $2.47 \mathrm{eV}$ for P2. The electrochemical behavior of the poly-azomethine $\mathbf{P 2}$ is probably due to the electron-withdrawing nature of the azomethine $(-\mathrm{CH}=\mathrm{N}-)$ bond [44]. Indeed, it was evidenced that introducing such group in $\pi$-conjugated molecules increases both the ionization potential and the electron affinity [45].

Table 2. Electrochemical onset potentials and electronic energy levels of P1 and P2.

\begin{tabular}{cccccc}
\hline Compound & $\mathbf{V}_{\text {onset-ox }}(\mathbf{V})$ & $\mathbf{V}_{\text {onset-red }}(\mathbf{V})$ & $\boldsymbol{E}_{\text {Hомо }}(\mathbf{e V})^{a}$ & $\boldsymbol{E}_{\text {LUMO }}(\mathbf{e V})^{b}$ & $\boldsymbol{E}_{\text {g-el }}(\mathbf{e V})^{c}$ \\
\hline P1 & 1.09 & -1.40 & -5.43 & -2.94 & 2.49 \\
\hline P2 & 1.20 & -1.27 & -5.54 & -3.07 & 2.47
\end{tabular}

${ }^{\mathrm{a}}$ Highest occupied molecular orbital ; ${ }^{\mathrm{b}}$ Lowest unoccupied molecular orbital ; ${ }^{\mathrm{c}}$ Electrochemical band-gap. 
The relative positions of the molecular orbital energy levels of the two conjugated materials relative to vacuum are presented in Figure S.7 and compared to the electronic energy levels of MEH-PPV, ITO, $\mathrm{Ca}, \mathrm{Al}$ and $\mathrm{Au}$ in order to facilitate the selection of the electrodes materials for the charge injection in OLEDs [46] and organic field effect transistors (OFET) [47].

\subsection{Electrical properties}

Schottky single-layer diodes and bottom-contact bottom-gate configuration OFETs using the two polymers as active layers were elaborated. The output and transfer plots of the elaborated devices exhibited typical diode and OFET behavior for P1 and a total loss of the hole mobility in $\mathbf{P 2}$ thin films.

\subsubsection{Charge transport mechanism}

The current density-voltage $(\mathrm{J}-\mathrm{V})$ characteristics of the macromolecule $\mathbf{P 1}$ were extracted at room temperature from single-layer device with [ITO/P1/Al] structure and were presented in table 3. The $\mathrm{J}-\mathrm{V}$ curve in linear scale (Figure 3 (b)) indicates a low threshold bias voltage of $1.85 \mathrm{~V}$. In logarithmic scale, the J-V characteristics of $\mathbf{P 1}$ based single layer device (Figure $\mathbf{3}$ (a)) were used to extract the conduction mechanisms.

(a)

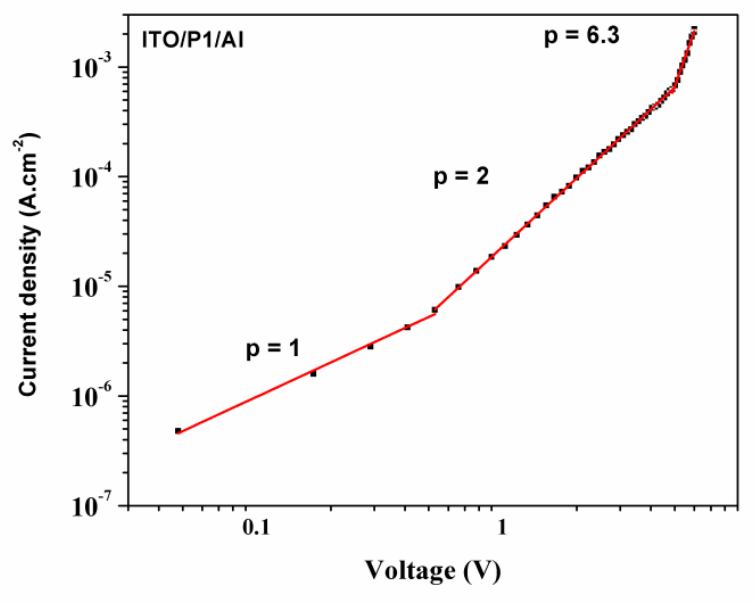

(b)

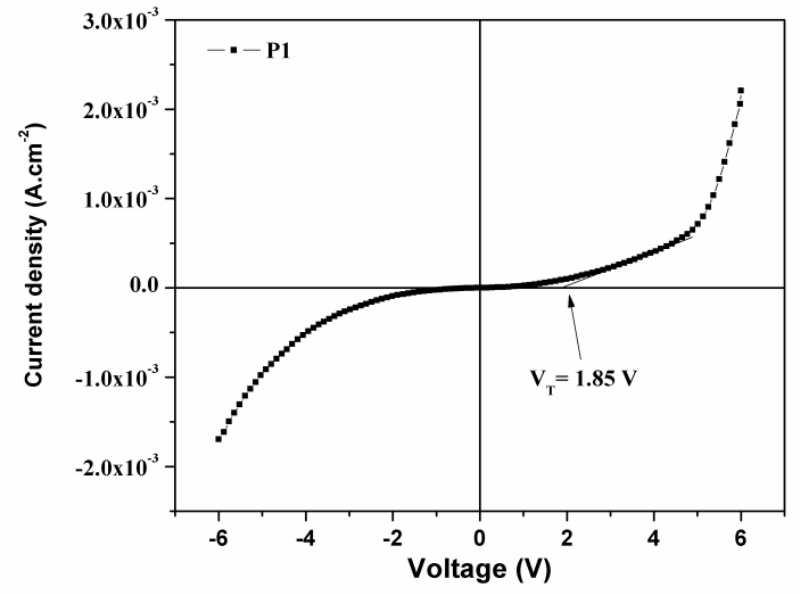

Figure 3. The $\mathrm{J}-\mathrm{V}$ characteristic for the [ITO/P1/Al] diode in logarithmic (a) and linear (b) scales

We can distinguish three regions with three different conduction regimes:

First region: at low voltage $(\mathrm{V}<0.53 \mathrm{~V})$ the regime is said Ohmic where the conduction is produced by the movement of holes in the valence band and electrons in the conduction band. In this case, a linear dependence exists between the applied voltage and the current density which follows the equation $[48,49]$ :

$$
J_{\Omega}=q \cdot p_{0} \cdot \mu \cdot V / d \boldsymbol{E q}(1)
$$


Where $\mathrm{V}$ is the applied voltage, $\mu$ is the charge mobility, $\mathrm{q}$ is the electronic charge, $p_{0}$ is the density of the free carrier and $\mathrm{d}$ is the thickness of the film.

Second region: at medium voltage $(0.53 \mathrm{~V}<\mathrm{V}<5.03 \mathrm{~V})$ the current density is space-charge limited (SCLC) and the current density is following [50]:

$$
J_{S C L C}=\frac{9}{8} \cdot \varepsilon \cdot \mu_{e f f} \cdot V^{2} / d^{3} \boldsymbol{E} \boldsymbol{q}(2)
$$

$\mathcal{E}$ is the permittivity of the organic material ( $\mathcal{E}$ is equal to $4 \varepsilon_{0}$ where $\varepsilon_{0}$ is the vacuum's permittivity). The $\mu_{\text {eff }}$ is the effective charge carrier mobility and is equal to $\theta \mu$ ( $\theta$ is the fraction of free charge $\left(\theta=p /\left(p+p_{t}\right)\right.$ where $p_{t}$ and $p$ are respectively trapped and free charge-carrier densities).

Third region: at higher voltages $(\mathrm{V}>5.03 \mathrm{~V})$, free carriers that are injected again cannot be trapped, inducing a fast increase of the current intensity [51] and a trap filled SCLC regime with $\mathrm{J}-\mathrm{V}^{\mathrm{m}}$ was measured $(\mathrm{m}=6)$.

The hole effective mobility $\left(\mu_{e f f}\right)$ in the $\mathbf{P 1}$ film was found higher than $510^{-6} \mathrm{~cm}^{2} / \mathrm{V} . \mathrm{s}$ (Table $\mathbf{3}$ ) by fitting the J-V characteristics to the SCLC model (Eq (2)). The estimated charge-carrier mobility is higher than the hole mobility in PVK which is between $10^{-7}$ and $10^{-6} \mathrm{~cm}^{2} \mathrm{~V}^{-1} \mathrm{~s}^{-1}$ [52] and comparable to the achieved hole mobility in the MEH-PPV based device $\left(\approx 10^{-5} \mathrm{~cm}^{2} / \mathrm{V} . \mathrm{s}\right)$ [53].

Table 3. Dynamic resistances $(\mathrm{Rd})$, threshold bias voltages $(\mathrm{Vs})$ and the charge carrier values for the [ITO/P1/Al] diodes

\begin{tabular}{lc}
\hline & {$[\mathrm{ITO} / \mathrm{P} 1 / \mathrm{Al}]$} \\
\hline Dynamic resistance $\mathrm{Rd}(\mathrm{k} \Omega)$ & 4.1 \\
\hline Threshold bias voltages Vs $(\mathrm{V})$ & 1.85 \\
\hline Charge carrier mobility $\left(\mathrm{cm}^{2} / \mathrm{V} . \mathrm{s}\right)$ & $5.110^{-6}$ \\
\hline
\end{tabular}

\subsubsection{Organic Field-Effect Transistors (bottom-contact bottom-gate)}

The output (Figure 4 (Left)) and transfer (Figure 4 (Right)) plots of P1 based device showed the characteristics of typical p-type OFET. The threshold voltage $\left(\mathrm{V}_{\mathrm{T}}\right)$ was calculated using the $\sqrt{-I_{D S}}-\mathrm{Vg}$ characteristics (Where $\mathrm{I}_{\mathrm{DS}}$ and $\mathrm{V}_{\mathrm{G}}$ are respectively the source-drain current and the gate voltage) by locating the intersection of the linear extrapolation of the curve at its maximum slope point with the $\mathrm{Vg}$ axis and the found value was $\mathrm{V}_{\mathrm{T}}=41 \mathrm{~V}$ (Figure 4 (Right)). The hole mobility $(\mu)$ was extracted from the transfer characteristics of the OFET in the saturation regime, at a drain voltage $\left(\mathrm{V}_{\mathrm{DS}}\right)$ equal to $-80 \mathrm{~V}$ using the following equation: 
$\mathrm{I}_{\mathrm{DS}}=(\mathrm{W} / 2 \mathrm{~L}) \mathrm{C}_{\mathrm{i}}\left(\mathrm{V}_{\mathrm{G}}-\mathrm{V}_{\mathrm{T}}\right)^{2}$ where $\mathrm{C}_{\mathrm{i}}$ is the capacitance per unit area of the $\mathrm{SiO}_{2}$ film, $\mathrm{L}$ and $\mathrm{W}$ are the length and width of the channel [54].
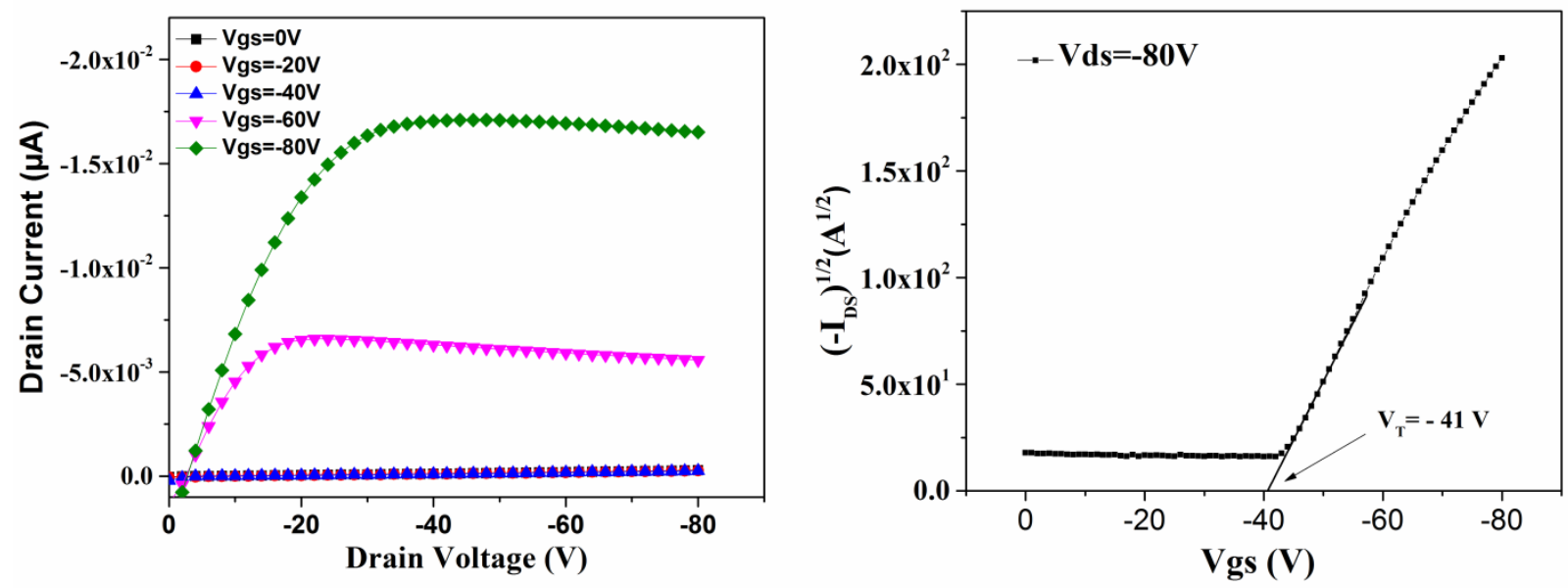

Figure 4. Typical output curves (a) and transfer plots (b) of the bottom-gate/bottom-contact

\section{OFET devices for $\mathbf{P 1}$}

The calculated hole mobility $(\mu)$ is in the order of $(6.9 \pm 0.17) \times 10^{-6} \mathrm{~cm}^{2} / \mathrm{V}$.s and the $\mathrm{I}_{\mathrm{on}} / \mathrm{I}_{\text {off }}$ ratio is equal to 1200 . For isotropic charge transport in organic semiconductors, charge-carrier mobilities measured by SCLC devices are smaller than those measured in OFET. In another words, the inplane hole mobility is higher than the out-of-plane one. This is mainly due to the fact that the mobility increases with the charge-concentration that is higher in OFETs compared to SCLC devices [30].

\subsection{Impact of acidic conditions on optical and electrical characteristics of $\mathbf{P} 2$}

With the aim of studying the PET phenomenon in P2, the optical properties of this polyazomethine have been studied in the presence of trifluoroacetic acid. The addition of TFA led to a visual remarkable color change from colorless to purple (Figure 5 (a)). Besides, a blue emission under $365 \mathrm{UV}$ excitation was accomplished (Figure 5 (b)). The chromaticity coordinates in the 1931 CIE diagram of the emitted light are $\mathrm{x}=0.22$ and $\mathrm{y}=0.34$ (Figure 5 (c)). 


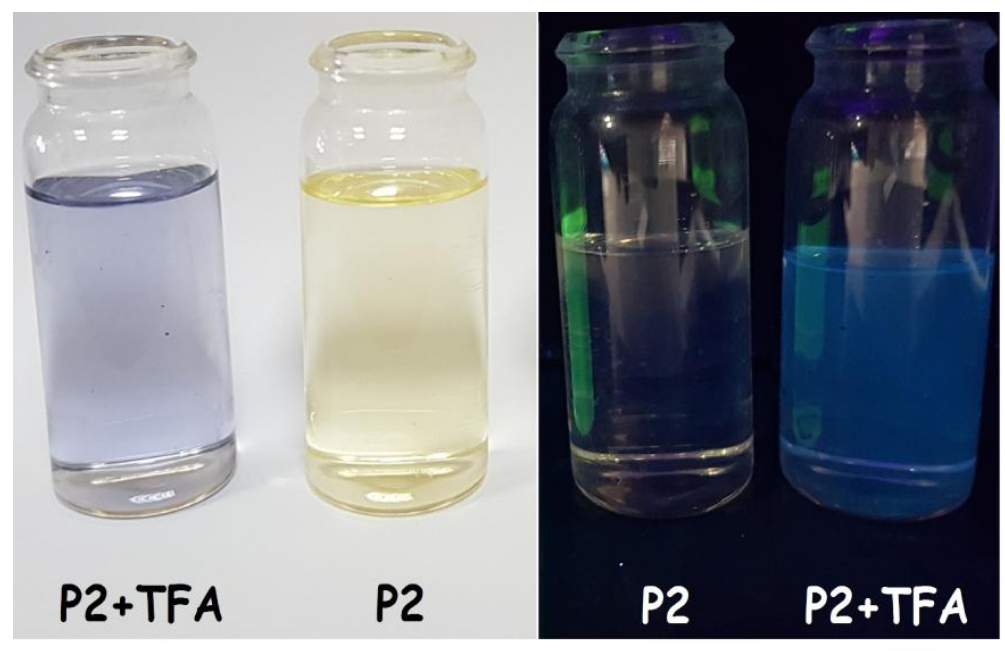

(a) (b)

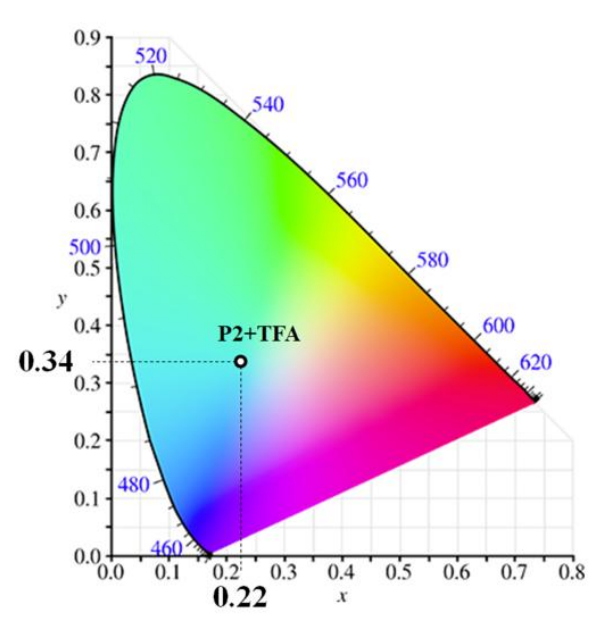

(c)

Figure 5. The photograph of $\mathbf{P 2}$ alone and in the presence of TFA $(5 \mu \mathrm{M})$ under white light (a), under UV illumination (b) and the chromaticity coordinates of the emitted light of P2 in the presence of TFA (c)

As shown in Figure 6 (a) the absorption spectrum of the chloroform diluted solution of $\mathbf{P 2}$ has undergone a hypochromic effect when adding TFA. Indeed, the protonation of the azomethine bridges creates an iminium ion, which prevents the $n-\pi *$ transitions causing the disappearance of the related absorption band. In the other hand, the formation of the iminium ion blocks the PET process, which generated the "turn-on" of the fluorescence in P2 (Figure 7). It is important to note that the intensity of the emitted fluorescence is a linear function of the amount of TFA added to the $\mathbf{P 2}$ solution (Figure 6 (b)). In fact, such functional molecular structures revealing "Switch-On" photoluminescence system are promising materials for proton (acid) and metal optical sensors [55]. 
(a)

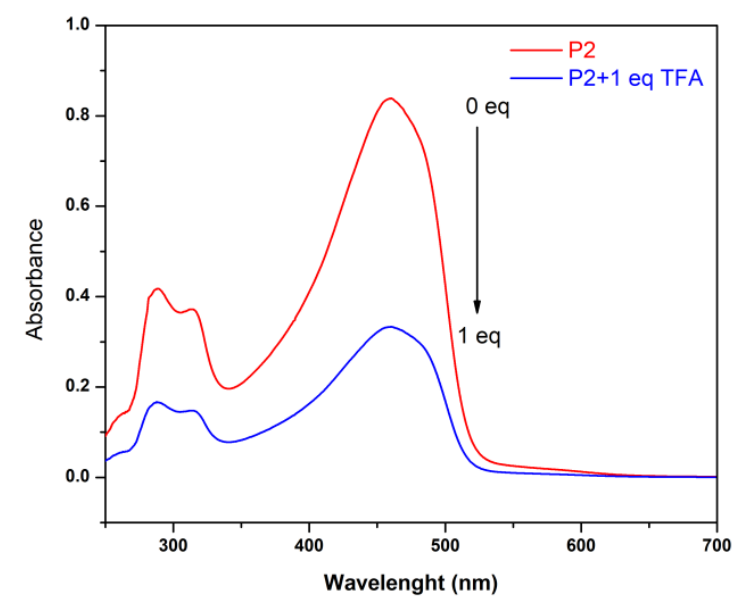

(b)

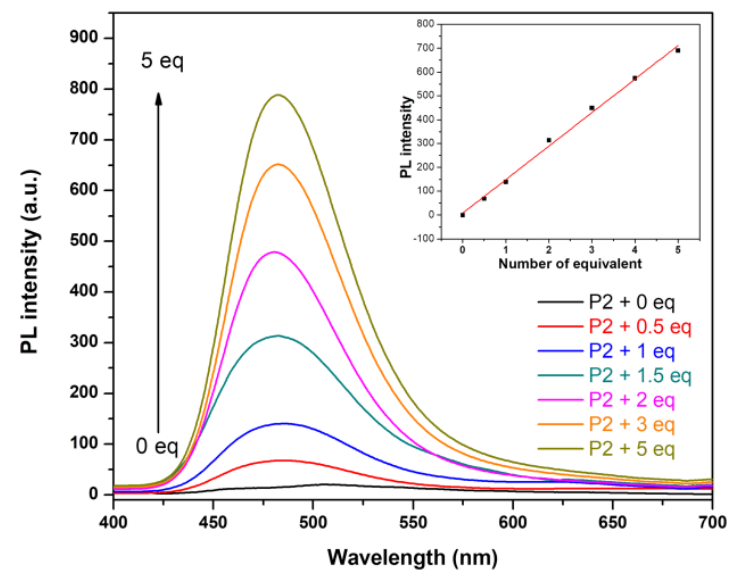

Figure 6. Effects of increasing concentration of acid (TFA) on the absorption profile (a) and on the emission profile (b) of $\mathbf{P 2}$ in chloroform solvent. (Sample concentrations are $5 \times 10^{-5} \mathrm{M}$ for the absorption and $2 \times 10^{-6}$ for the PL)

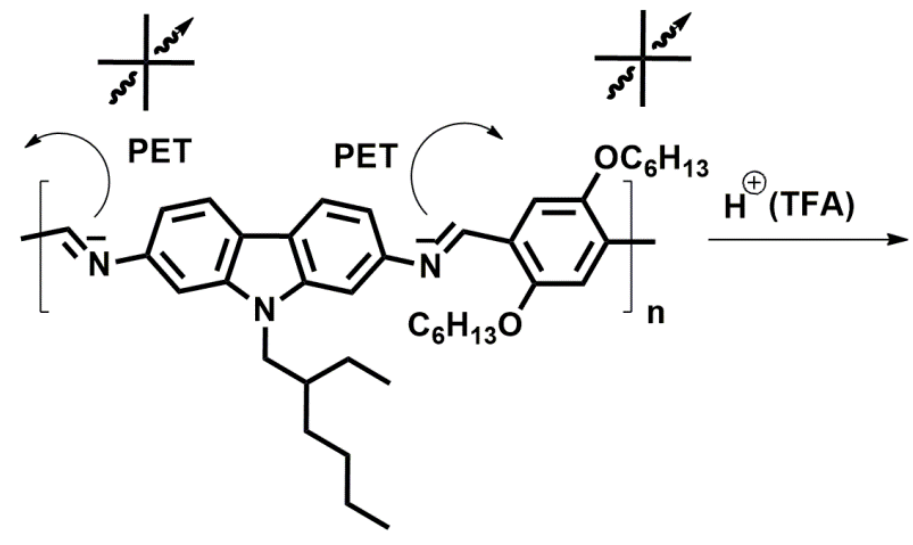

Nonfluorescence OFF

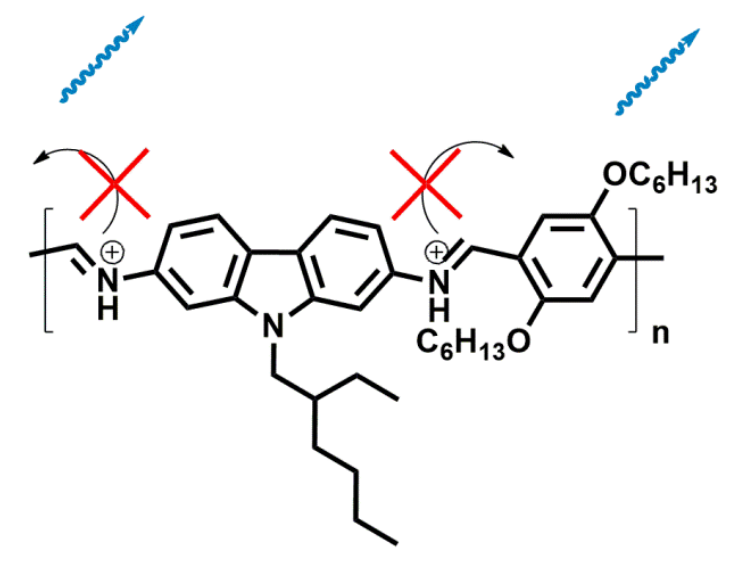

Fluorescence $\mathrm{ON}$

Figure 7. Switch-on fluorescence mechanism of $\mathbf{P 2}$ in acid condition.

The electrical devices showed a total loss of the hole mobility in the $\mathbf{P 2}$ thin film. In order to generate the charge transport in the P2 single layer diode device, two substrates with P2/ITO/glass configuration were prepared and exposed to TFA in vapor for 5 seconds (sample: P2 + TFA) and 10 seconds (sample: P2 + 2TFA). Aluminum top electrodes were then deposited to obtain single layer diode devices Schottky type containing protonated P2 thin film. The J-V (current density-voltage) curves of the P2 doped films in linear and logarithmic scales are presented respectively in Figure 8 (a) and Figure 8 (b and c). Key findings demonstrate that protonating with TFA generates charge-transport in poly-azomethine thin films. From these features, it is clear that this behavior is directly correlated to the formation of the iminium ion. 
Indeed, protonating azomethine bridges is a doping method which creates free charge carriers and increases the hole effective mobility [15]. The calculated hole effective mobilities in the doped P2 thin films $\left(\mu_{e f f}\right)$ are of $3.18 \times 10^{-5} \mathrm{~cm}^{2} / \mathrm{V} . \mathrm{s}$ and $7 \times 10^{-5} \mathrm{~cm}^{2} / \mathrm{V} . \mathrm{s}$ for [ITO/P2+TFA/Al] and [ITO/P2+2TFA/Al] diodes, respectively.

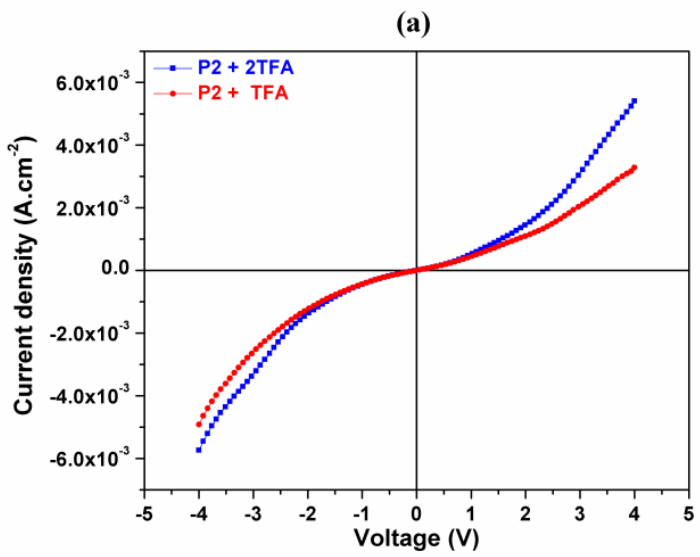

(b)

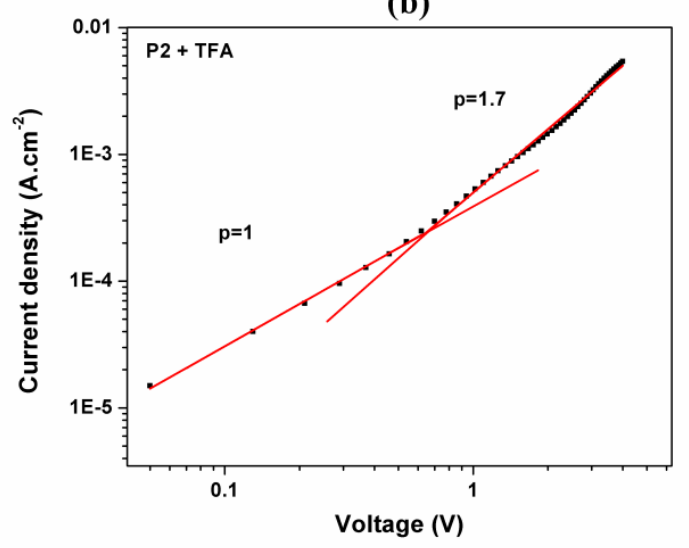

(c)

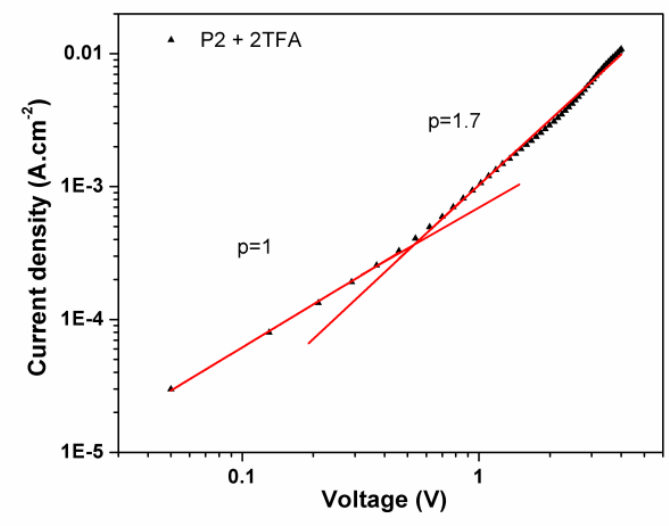

Figure 8. The $\mathrm{J}-\mathrm{V}$ characteristic for the $[\mathrm{ITO} / \mathbf{P 2}+\mathbf{T F A} / \mathrm{Al}]$ and $[\mathrm{ITO} / \mathbf{P 2}+\mathbf{2 T F A} / \mathrm{Al}]$ diodes in linear (a) and logarithmic (b and c) scales

\section{Conclusion}

Two novel carbazole-based polymers involving vinylene (P1) and azomethine (P2) $\pi$-linkers were synthesized and investigated. The replacement of vinylene bridge $(-\mathrm{CH}=\mathrm{CH}-)$ between hydroquinone and carbazole moieties in $\mathbf{P 1}$ by the azomethine $(-\mathrm{CH}=\mathrm{N}-)$ linkages in $\mathbf{P 2}$ increased significantly the thermal stability of the macromolecule. P1 is a yellowish-green fluorescent polymer, while a very weak fluorescence, related to a photo-induced electron transfer (PET), was observed in P2. The cyclic voltammetry analysis of the polymers showed a reduction in the electrochemical gap of $\mathbf{P 2}$ compared to $\mathbf{P 1}$, due to the electron-withdrawing effect of the azomethine $(-\mathrm{CH}=\mathrm{N}-)$ bridges. The electrical devices showed good charge carrier mobility for $\mathbf{P 1}$ thin film, while a total loss of the mobility was observed in $\mathbf{P 2}$. Though, the 
poly-azomethine $\mathbf{P 2}$ exhibited high sensitivity toward the trifluoroacetic acid (TFA). Indeed, the addition of TFA to $\mathbf{P 2}$ diluted solution induced a significant photoluminescence turn-on. Besides, the hole mobility in $\mathbf{P 2}$ thin films was regenerated and significantly enhanced by exposition to the TFA vapors. Further research on elaboration of OLEDs using P1 as active layer and on the development of chemical sensors based on $\mathbf{P 2}$ are in progress.

\section{Acknowledgements}

This work was supported by the Research Deanship of the University of Hail-Saudi Arabia through project number RG-20 110.

\section{References}

[1] A. Upadhyay, S. Karpagam, Movement of new direction from conjugated polymer to semiconductor composite polymer nanofiber, Rev. in Chem. Eng. 35 (2019) 351-375.

[2] D. Jemmeli, M. Belhaj, B. Ben Salem, N. Jaballah, R. Yatskiv, C. Dridi, J. Grym, M. Majdoub, PPV derivative/ZnO nanorods heterojunction: Fabrication, Characterization and NearUV light sensor development, Materials Research Bulletin 106 (2018) 28-34.

[3] A. F. Al- Hossainy M. Bassyouni, M. Sh. Zoromba, Elucidation of Electrical and Optical Parameters of Poly(o-anthranilic acid)-poly(o-amino phenol)/Copper Oxide Nanocomposites Thin Films, J. Inorg. Organomet. Polym. 28 (2018) 2572-2583.

[4] S.J. Zou, Y. Shen, F.M. Xie, J.D. Chen, Y.Q. Li, J.X. Tang, Recent advances in organic lightemitting diodes: toward smart lighting and displays, Mater. Chem. Front. 4 (2020) 788-820.

[5] M. Li, J. Wang, W. Xu, L. Li, W. Pisula, R. A.J. Janssen, M. Liu, 2021. Noncovalent semiconducting polymer monolayers for high-performance field-effect transistors, Progress in Polymer Science 117, 101394.

[6] C. Lee, S. Lee, G.U. Kim, W. Lee, B. J. Kim, Recent Advances, Design Guidelines, and Prospects of All-Polymer Solar Cells, Chem. Rev. 119 (2019) 8028-808.

[7] K. Mahesh , S. Karpagam, K. Pandian, How to Design Donor-Acceptor Based Heterocyclic Conjugated Polymers for Applications from Organic Electronics to Sensors. Top Curr Chem (Z) 377 (2019) 12.

[8] A. F. Al-Hossainy, A. Ibrahim, The effects of annealing temperature on the structural properties and optical constants of a novel DPEA-MR-Zn organic crystalline semiconductor nanostructure thin films, Optical Materials 73 (2017) 138-153. 
[9] H. Ling, S. Liu, Z. Zheng, F. Yan, 2018. Organic Flexible Electronics, Small Methods 2, 1800070.

[10] L. Giraud, S. Grelier, E. Grau, G. Hadziioannou, C. Brochon, H. Cramail, E. Cloutet, Upgrading the chemistry of $\pi$-conjugated polymers toward more sustainable materials, J. Mater. Chem. C 8 (2020) 9792-9810.

[11] X. Dong H. Wang, J. Huo, S. Liu, H. Shi. F. Cheng. B. Z. Tang, 2021, Synthesis, crystal structure, aggregation-induced emission enhancement and electroluminescence properties of a novel compound containing carbazole and triarylborane groups, J. Mol. Struct. 1228, 129721.

[12] B. Çiçek, Ü. Çalışır, M. Tavaslı, R. Tülek, A. Teke, Synthesis and optical characterization of novel carbazole Schiff bases, J. Mol. Struct. 1153 (2018) 42-47.

[13] V. Mohankumar, P. Pounraj, M. Senthil Pandian, P. Ramasamy, Tuning the lifetime from molecular engineering of carbazole donor based metal-free organic dyes for dye sensitized solar cells e A computational approach, J. Mol. Struct. 1195 (2019) 494-505.

[14] M. Laajimi, A. Jebnouni, M.Chemli, M. Majdoub, R. Ben Chaabane, Optical, dielectric and oxygen sensing properties of an anthracene and carbazole based $\pi$-conjugated Schiff base, Mater. Chem. Phys. 228 (2019) 336-343.

[15] P-L. T. Boudreault, S. Beaupré, M. Leclerc, Polycarbazoles for plastic electronics, Polym. Chem. (1) (2010) 127-136.

[16] J.F. Morin, M. Leclerc, D. Adès, A. Siove, Polycarbazoles: 25 Years of Progress, Macromol. Rapid Commun. 2005, 26, 761-778.

[17] S.H. Park, A. Roy, S. Beaupré, S. Cho, N. Coates, J.S. Moon, D. Moses, M. Leclerc, K. Lee, A.J. Heeger, Bulk heterojunction solar cells with internal quantum efficiency approaching 100\%. Nature Photon (3) (2009) 297-302.

[18] G. Garbay, L. Muccioli, E. Pavlopoulou, A. Hanifa, G.Hadziioannouabc, Brochon, E. Cloutet, Carbazole-based $\pi$-conjugated polyazomethines: Effects of catenation and comonomer insertion on optoelectronic features, Polymer (119) (2017) 274-284.

[19] A. Iwan, D. Sek, Processible polyazomethines and polyketanils: From aerospace to lightemitting diodes and other advanced applications, Prog. Polym. Sci. (33) (2008) 289-345.

[20] P. Sen, T. Nyokong, Enhanced Photodynamic inactivation of Staphylococcus Aureus with Schiff base substituted Zinc phthalocyanines through conjugation to silver nanoparticles, J. Mol. Struct. (1232) (2021) 130012. 
[21] Ö. Özdemir, f Synthesis and characterization of a new diimine Schiff base and its $\mathrm{Cu} 2+$ and $\mathrm{Fe} 3+$ complexes: Investigation of their photoluminescence, conductance, spectrophotometric and sensor behaviors, J. Mol. Struct. (1179) (2019) 376-389.

[22] C. Garcias-Morales, J. E. Maldonado, A. A. Castolo, C. M. P. Berumen, M. A. Lobato, M. A. Rodriguez, A. E. Roa, Synthesis and physicochemical characterization of Schiff bases used as optical sensor for metals detection in water, J. Mol. Struct. (1228) (2021) 129444.

[23] I. Kaya, M. Yıldırım, A. Aydın, D. Senol, Synthesis and characterization of fluorescent graft fluorene-co-polyphenol derivatives: The effect of substituent on solubility, thermal stability, conductivity, optical and electrochemical properties, React. Funct. Polym. 70 (10) (2010) 815-826.

[24] O. Thomas, O. Inganas, M.R. Andersson, Synthesis and Properties of a Soluble Conjugated Poly(azomethine) with High Molecular Weight, Macromolecules 315 (8) (1998) 2676-2678.

[25] A. Jebnouni, M. Chemli, P. Leveque, S. Fall, M. Majdoub, N. Leclerc, Effects of vinylene and azomethine bridges on optical, theoretical electronic structure and electrical properties of carbazole and anthracene based $\pi$-conjugated molecules, Org. Electron. (56) (2018) 96-110.

[26] G. Krucaitea, L. Liub, D.Tavgenienea, L. Peciulytea, J. V. Grazuleviciusa, Z. Xieb. B. Zhangb, S. Grigalevicius, Electroactive polymers containing 3-arylcarbazolyl units as hole transporting materials for OLEDs, Opt. Mater. 42 (2015) 94-98.

[27] R. Griniene, L. Liu, D. Tavgeniene, D. Sipaviciute, S. Grigalevicius, Polyethers with pendent phenylvinyl substituted carbazole rings as polymers for hole transporting layers of OLEDs, Opt. Mater. 51 (2016) 148-153.

[28] H. Huang, C. Karlsson, F. Mamedov, M. Strømme, A. Gogoll, and M. Sjödin, Polaron Disproportionation Charge Transport in a Conducting Redox Polymer J. Phys. Chem. C 2017, 121 (24) 13078-13083.

[29] C. S. Marvel and N. Tarkoy, Heat Stability Studies on Chelates from Schiff Bases of Salicylaldehyde Derivatives, J. Am. Chem. Soc. 79 (22) (1957) 6000-6002.

[30] S. Fall, L. Biniek, Y. Odarchenko, D.V. Anokhin, G. de Tournadre, P. Lévêque, N. Leclerc, D. A. Ivanov, O. Simonetti, L. Giraudet and T. Heiser, Tailoring the microstructure and charge transport in conjugated polymers by alkyl side-chain engineering, J. Mater. Chem. C (4) (2016) 286-295.

[31] N. Drolet, J.-F. Morin, N. Leclerc, S. Wakim, Y. Tao, M. Leclerc, 2,7-CarbazolenevinyleneBased Oligomer Thin-Film Transistors: High Mobility Through Structural Ordering, Adv. Funct. Mater. 15 (10) (2005) 1671-1682. 
[32] B. Ben Salem, K. Hriz, N. Jaballah, D. Kreher, M. Majdoub, New semi-conducting poly(phenylene vinylene-alt-anthrylene vinylene)s: Synthesis, characterization and photophysical properties, Opt. Mater. (50) Part B (2015) 114-122.

[33] J. Tauc, R. Grigorovici, A. Vancu, Properties and Electronic Structure of Amorphous Germanium, Phys. Stat. Solid. b 15 (1966) 627-637.

[34] K. Kim, Y-R. Hong, S-W. Lee, J-I. Jin, Y. Park, B-H. Sohn, W-H. Kim and J-K. Park, Synthesis, and luminescence properties of poly(p-phenylenevinylene) derivatives carrying directly attached carbazole pendants, J. Mater. Chem. (11) (2001) 3023-3030.

[35] C.P. Chang, C.C. Wang, C.Y. Chao, M.S. Lin, Comparisons of Optical Properties on Metaand Para-Linkages of Copolymers for Poly(phenylene vinylene) and Poly(phenylene azomethine) with Alkylthio Group at the Side Chain, J. Polym. Res. 12 (1) (2005) 1-7.

[36] Y.F. Huang, Y.J. Shiu, J.H. Hsu, S.H. Lin, A.C. Su, K.Y. Peng, S.A. Chen, W.S. Fann, J. Phys. Chem. C 111, 5533 (2007).

[37] D. Frath, P. Didier, Y. Mély, J. Massue, G. Ulrich, Vectorization and Intracellular Distribution of a Two-Photon-Absorbing, Near-Infrared-Emitting $\pi$-Extended Boranil Dye, ChemPhotoChem 1 (4) (2017) $109-112$.

[38] D. Maity, S. Dey and P. Roy, A two-pocket Schiff-base molecule as a chemosensor for $\mathrm{Al}^{3+}$ New J. Chem. (41) (2017) 10677-10685.

[39] L. Wang, W. Qin, W. Liu, Two highly sensitive Schiff-base fluorescent indicators for the detection of Zn2+, Anal. Methods. 6 (4) (2014) 1167-1173.

[40] M. J. Culzoni, A. Muñoz de la Peña, A. Machuca, H. C. Goicoechea and R. Babiano, Rhodamine and BODIPY chemodosimeters and chemosensors for the detection of $\mathrm{Hg} 2+$, based on fluorescence enhancement effects Anal. Methods 5 (1) (2013) 30-49.

[41] L. Tang, D. Wu, X. Wen, X. Dai, K. Zhong, A novel carbazole-based ratiometric fluorescent sensor for $\mathrm{Zn} 2+$ recognition through excimer formation and application of the resultant complex for colorimetric recognition of oxalate through IDAs, Tetrahedron (70) (47) 2014, 9118-9124.

[42] B. K. Rani, S. A. John, Pyrene-antipyrine based highly selective and sensitive turn-on fluorescent sensor for Th(IV), New J. Chem. (41) (2017) 12131-12138.

[43] J. L. Bredas, R. Silbey, D. S. Bordeaux, R. R. Chance, Chain-length dependence of electronic and electrochemical properties of conjugated systems: polyacetylene, polyphenylene, polythiophene, and polypyrrole, J. Am. Chem. Soc. 105 (22) (1983) 6555-6559. 
[44] S. Teka, K. Hriz, N. Jaballah, D. Kreher, F. Mathevet, N. Jarroux, M. Majdoub, Mater. Sci. Semicond. Process. (34) (2015) 189-197.

[45] M. Ranger, D. Rondeau, M. Leclerc, New Well-Defined Poly(2,7-fluorene) Derivatives: Photoluminescence and Base Doping, Macromolecules 30 (25) (1997) 7686-7691.

[46] M. Chemli, A. H. Saïd, N. Jaballah, J. L. Fave, M. Majdoub, Synthesis and characterization of new electroluminescent poly(p-phenylene) derivative, Synth. Met. (161) (2011) 1463- 1468. [47] W. Zhong, J. Xu, S. Sun, J. Liang, B. Zhang, R. He, L. Lan, F. Huang, L. Ying, W. Yang, J. Peng, Y. Cao, Effects of bridge units on the properties of indolo[3,2-b]carbazole-codifluorobenzo[d][1,2,3]triazole based $\pi$-conjugated copolymers Org. Electron. (23) (2015) 17-23. [48] H. Hrichi, K. Hriz, M. Benzarti-Ghédira, N. Jaballah, R. Ben Chaâbane, M. Majdoub, H. Ben Ouada, Optical and electrical characterization of thin films based on anthracene polyether polymers, Mater. Sci. Semicond. Process. (16) (2013) 851-858.

[49] H. Saidi, N. Dhahri, W. Aloui, A. Bouazizi, T. Boubaker, R. Goumont, Investigation of optical and electrical properties of p-nitro-benzylidenemalononitrilethin films for optoelectronic applications, Superlattices and Microstructures (120) (2018) 193-198.

[50] H Hrichi, K. Hriz, N. Jaballah, R. Ben Chaâbane, O. Simonetti, M. Majdoub, New anthracene-based soluble polymers: optical and charge carrier transport properties, J. Polym. Res. 20 (2013) 241.

[51] N. Jaballah, M. Chemli, J.L. Fave, M. Majdoub, New bithiophene-containing electroluminescent polymer: Synthesis, characterization, optical and electrical properties, Opt. Mater. (50) Part B (2015) 144-153.

[52] M. B. Khalifa, D. Vaufrey, A. Bouazizi, J. Tardy, H. Maaref, Hole injection and transport in ITO/PEDOT/PVK/Al diodes, Mater. Sci. Eng. C 21 (2002) 277 - 282.

[53] C.A. Amorim, M.R. Cavallari, G. Santos, F.J. Fonseca, A.M. Andrade, S. Mergulhão, Determination of carrier mobility in MEH-PPV thin-films by stationary and transient current techniques, J. Non-Cryst. Solids (358) (2012) 484-491.

[54] A. Ganguly, S. Ghosh, S. Kar, N. Guchhait, Selective fluorescence sensing of Cu(II) and $\mathrm{Zn}$ (II) using a simple Schiff base ligand: Naked eye detection and elucidation of photoinduced electron transfer (PET) mechanism, Spectrochim. Acta Mol. Biomol. Spectrosc. (143) (2015) 72-80.

[55] I. H. Hwang, Y. W. Choi, K. B. Kim, G. J. Park, J. J. Lee, L. T. Nguyen, I. Noh, C. Kim, A highly selective and sensitive fluorescent turn-on $\mathrm{Al}^{3+}$ chemosensor in aqueous media and living cells: experimental and theoretical studies, New J. Chem. (40) (2016) 171-178. 
